\title{
Factors associated with obesity in Iranian elderly people: Results from the National Health Survey
}

Enayatollah Bakhshi ${ }^{1 *}$, Behjat Seifi ${ }^{2}$, Akbar Biglarian $^{1}$ and Kazem Mohammad ${ }^{3}$

\begin{abstract}
Background: No studies have been carried out so far to cover the association between factors related to obesity, in a representative sample of the Iranian elderly population.

Methods: The data in this investigation were taken from the National Health Survey in Iran, which included 4380 people aged 60 and older. The logistic regression was applied to model the relationship between the odds of obesity and age, sex, education level, place of residence, smoking and marital status.

Results: Obesity odds ratios were 1.96 (95\% Cl: 1.53-2.52) for women, 2.16 (95\% Cl: 1.71-2.72) for the subjects living in urban areas and 0.68 (95\% Cl: $0.47-0.97)$ for smokers. Regarding the people aged 60-64 years as the reference group, the obesity odds ratios were 0.86 (95\% Cl: 0.66-1.10) for ages $65-69$ years, 0.75 (95\% Cl: 0.57-0.97) for ages $70-74$ years, 0.43 (95\% Cl: 0.30-0.60) for ages $75-79$ years and 0.36 (95\% Cl: $0.20-0.63$ ) for ages $80+$ years. Using the basic education level as the reference group, obesity odds ratios were 1.38 (95\% Cl: 1.08-1.76) for the moderate level and 0.92 (95\% Cl: 0.56- 1.52) for the high level group.

Conclusions: As the result of findings, we are optimistic that we would be able to contribute to the aged community of the society, which could be achieved by means of better treatments and reductions in the rate of obesity.
\end{abstract}

\section{Background}

Obesity has been called the disease of the twenty-first century. Nearly 1.5 billion adults of age 20 and older are considered to be overweight or obese. Of which, nearly 300 million women and more than 200 million men are obese [1]. The prevalence of obesity is also increasing in older populations throughout the world [2]. The prevalence of obesity among elderly people in industrialized countries estimates suggest ranging from $15 \%$ to over $30 \%[3,4]$.

Obesity has been reported to be a risk factor for cardiovascular diseases, diabetes, hypertension, some cancers and also some other diseases [5-19]. In general, obesity is related to morbidity, mortality as well as poor quality of life [20]. Although some studies showed that the impact of obesity on mortality may have decreased over time [21], obese elderly people are more likely to

\footnotetext{
* Correspondence: Bakhshi@razi.tums.ac.ir

'Department of Statistics and Computer, University of Social Welfare and Rehabilitation Sciences, Tehran, Iran

Full list of author information is available at the end of the article
}

become disabled than elderly people at a normal weight [22].

Obesity has been linked to a variety of factors. Himes [23] found that older men are less likely than older women to be obese but Kaplan et al. [24] found that older men are more likely to be obese. Although some studies showed that the prevalence of obesity is going up in all age groups, including older people [25], another study suggested that in industrialized countries, people gain weight up to age of 50-60 and then BMI tends to decrease [26]. Flegal and colleagues have also found that the prevalence of obesity increases from 20 to 60 years of age and decreases after the age of 60 [27].

Another predictor for obesity in elderly people is marital status which has been analyzed in some studies but the findings are not consistent $[23,24]$.

The association of obesity in elderly people with smoking has been analyzed in some studies. An inverse association between smoking and obesity was observed in both sexes [28] but not meaningful among men [24].

Himes found that an inverse relationship between education and obesity [23] and Kaplan et al. showed
C Biomed Central

(c) 2011 Bakhshi et al; licensee BioMed Central Ltd. This is an open access article distributed under the terms of the Creative Commons Attribution License (http://creativecommons.org/licenses/by/2.0), which permits unrestricted use, distribution, and reproduction in any medium, provided the original work is properly cited. 
lower education as a factor which was associated with obesity in both sexes[24].

In Iran, it is commonly believed that overweight and obese people are lazy and gluttonous and they lack selfcontrol. A considerable number of obese people do not go out in public due to the fact that public facilities are very poor comfort levels. For example, the seats in the cinemas are too small for the subject population. Obese people are also more likely to lose the benefits of exercise, which may cause gaining further additional weight. They often feel inferior to others due to the fact that many people would not socialize with an obese person. In Some cases, it is believed that an obese person is taking up more space than he or she should and a job is often refused because of their weights. Until recently, no studies of the association between factors related to obesity have been carried out in a representative sample of the Iranian elderly population. Thus, it is time to invest more to address the issue and the factors related to obesity of the elderly people in this country. The aims of the present study were to explore the associations between age, sex, education level, place of residence, smoking, marital status and obesity among Iranian elderly men and women population. This study was carried out in a sample of men and women representative of the Iranian population older adults (age 60 and over) and adults (aged 20-59).

\section{Methods}

\section{Data set examined}

The National Health Survey in Iran (NHSI) is a survey designed to gain comprehensive knowledge and information about health care problems and difficulties throughout the country, 1999-2000. The survey was conducted under the supervision and with the financial support of the Iranian Ministry of Health and Medical Education. The population sample of the survey consisted of one thousandth of the total Iranian population; non-Iranians were excluded. They were randomly chosen by cluster sampling, each comprising of 8 households. The choice of 8 households for the cluster size was based on one-day performance capacity of the data collection group: Four people ( 2 physicians, 1 interviewer and 1 lab technician). The statistical framework was based on the household lists, which usually are updated annually and are available to get from every Health Department in the provinces [29-32]. All participants gave their written informed consent for participating the study. Our analytical sample was limited to 2201 women and 2179 men of age 60 and over in the NHSI and 11206 women and 10479 men aged 20-59 years. This study has been approved by the Ethic Committee of the University of Social Welfare and Rehabilitation Sciences.

\section{Model variables}

\section{a) Response variable}

Height and weight of the sample population were measured. BMI (Body Mass Index) was calculated as weight in kilograms divided by the square of the height in meters $\left(\mathrm{kg} / \mathrm{m}^{2}\right)$. Subjects were also classified into obese $\left(\mathrm{BMI} \geq 30 \mathrm{~kg} / \mathrm{m}^{2}\right)$ and non-obese $\left(\mathrm{BMI}<30 \mathrm{~kg} / \mathrm{m}^{2}\right)$.

\section{b) Independent variables}

i. Place of residence The subjects were grouped according to their place of residence as living in cities (urban) or villages (rural).

ii. Age (yr) Information about the respondents' age was based on their self-reported birth year. Adults were stratified into four 10-year age groups (20-29, 30-39, 40-49 and 50-59 years) and older adults into five age groups (60-64, 65-69, 70-74, 75-79 and 80+ years).

iii. Education Education was defined as the total number of years of education. The respondents were categorized into three groups: those with low (0-8 years), moderate (9-12 years) or high (more than 12 years) education levels. The three categories used two dummy variables.

iv. Smoking status Smoking status was dichotomized into smokers vs nonsmokers.

v. Marital status Divorced, widowed and those who have not married were coded as 0 (no spouse) vs others who lived with their spouse was coded 1 (spouse).

vi. Health shocks The respondents were grouped according to some health issues including diabetes, high blood pressure, asthma, arthritis and nervous diseases.

\section{Statistical analysis}

The distribution of independent variables and BMI groups were tested with $\chi^{2}$-test. The logistic regression was applied to model the relationship between the odds of a obesity and age, sex, place of residence, smoking, marital status and the education level. All independent variables were entered into a logistic model simultaneously to assess the predictive ability of each variable while controlling for all other variables. All 2-way interaction terms were dropped from the model because they were not statistically significant.

The results are presented as the odds ratios and their 95\% confidence intervals (CI). The Hosmer and Lemeshow test was used in this model to evaluate the significance of improved port with introduction of additional variables. All analyses were carried out by using the SPSS software Package, version 15.

\section{Results}

Among the 2201 female and 2179 male older adult subjects, the mean BMI were $25.13 \mathrm{~kg} / \mathrm{m}^{2}$ (SD = 4.96) and $23.64 \mathrm{~kg} / \mathrm{m}^{2}(\mathrm{SD}=3.92)$ for females and males, respectively. The mean BMI for urban older adults $(\mathrm{n}=2545)$ 
was $25.28 \mathrm{~kg} / \mathrm{m}^{2}(\mathrm{SD}=4.54)$ and for rural older adults $(\mathrm{n}=1835)$ was $23.15 \mathrm{~kg} / \mathrm{m}^{2}(\mathrm{SD}=4.23)$.

Overall, $11.2 \%$ of respondents were classified as obese. Table 1 displays the prevalence of obesity within categories of the independent variables. There were statistically significant differences between age groups, men and women, urban and rural, smokers and nonsmokers. Participants who had no spouse were more obese. The prevalence of obesity was higher among older adults

Table 1 The prevalence of obesity within categories of the risk factors in a random sample of adults age $\geq 60$ years ( $n=4380)$, National Health Survey in Iran, using $\chi^{2}$-test.

\begin{tabular}{|c|c|c|c|}
\hline \multirow[t]{2}{*}{ Variable } & \multicolumn{2}{|c|}{ Obesity } & \multirow[b]{2}{*}{$\mathrm{p}$-value } \\
\hline & No & $\%$ & \\
\hline \multicolumn{4}{|c|}{ Age group(years) } \\
\hline $60-64$ & 182 & 14.1 & \\
\hline $65-69$ & 128 & 12.3 & \\
\hline $70-74$ & 117 & 11.4 & $<0.001$ \\
\hline $75-79$ & 49 & 6.5 & \\
\hline $80+$ & 15 & 5.6 & \\
\hline \multicolumn{4}{|l|}{ Sex } \\
\hline Men & 150 & 6.9 & \\
\hline Women & 341 & 15.5 & $<0.001$ \\
\hline \multicolumn{4}{|c|}{ Place of Residence } \\
\hline Urban & 371 & 14.6 & \\
\hline Rural & 120 & 6.5 & $<0.001$ \\
\hline \multicolumn{4}{|l|}{ Smoking } \\
\hline Nonsmoker & 452 & 12.2 & \\
\hline Smoker & 39 & 5.9 & $<0.001$ \\
\hline \multicolumn{4}{|c|}{ Marrital Status } \\
\hline No spouse & 156 & 12.8 & \\
\hline Spouse & 335 & 10.6 & $=0.036$ \\
\hline \multicolumn{4}{|c|}{ Education level } \\
\hline Basic & 342 & 10.7 & \\
\hline Moderate & 128 & 13.2 & $=0.079$ \\
\hline High & 21 & 9.9 & \\
\hline \multicolumn{4}{|l|}{ Diabetes } \\
\hline No & 400 & 10 & \\
\hline Yes & 91 & 23.5 & $<0.001$ \\
\hline \multicolumn{4}{|c|}{ High Blood Pressure } \\
\hline No & 260 & 8.4 & \\
\hline Yes & 231 & 18.2 & $<0.001$ \\
\hline \multicolumn{4}{|l|}{ Asthma } \\
\hline No & 453 & 10.9 & \\
\hline Yes & 38 & 16.9 & $=0.006$ \\
\hline \multicolumn{4}{|l|}{ Arthritis } \\
\hline No & 156 & 7.5 & \\
\hline Yes & 335 & 14.6 & $<0.001$ \\
\hline \multicolumn{4}{|c|}{ Nervous Disorders } \\
\hline No & 452 & 11.2 & \\
\hline Yes & 39 & 11.2 & $=0.98$ \\
\hline
\end{tabular}

who had diabetes, high blood pressure, asthma or arthritis diseases.

Turning to the logistic regression analysis, Table 2 summarizes the adjusted odds ratios and their 95\% CI's. Using 60-64 years as the reference group, the obesity odds ratios for age groups 65-69, 70-74, 75-79 and 80+ years were 0.86 ( $95 \%$ CI: $0.66-1.10), 0.75$ (95\% CI: $0.57-$ 0.97), 0.43 (95\% CI: $0.30-0.60)$ and 0.36 (95\% CI: 0.20 $0.63)$, respectively.

In general, Women were more obese. The obesity odds ratio was 1.96 (95\% CI: 1.53-2.52) for women.

An association was observed between place of residence and obesity. The obesity odds ratio was 2.16 (95\% CI: 1.71-2.72) for urban participants.

We found a statistically significant inverse association between smoking and obesity. For smoker participants, the adjusted odds ratio was 0.68 (95\% CI: 0.47-0.97).

An association was observed between marital status and obesity (but non-significant). Obesity odds ratio was 1.17 (95\% CI: 0.92-1.48) for older adults who had spouse.

Using basic education as the reference group, obesity odds ratios for the moderate and high groups were 1.38

Table 2 Adjusted $^{a}$ odds ratios for obesity ${ }^{b}$ among 4380 Iranian older adults aged $\geq 60$ years, National Health Survey in Iran, in the logistic analysis

\begin{tabular}{ccc}
\hline variable & OR $^{\mathbf{c}}$ & $\mathbf{9 5 \%} \mathrm{Cl}^{\mathbf{d}}$ \\
\hline Age group(years) & 1.00 & \\
$60-64$ & 0.86 & $0.66-1.10$ \\
$65-69$ & 0.75 & $0.57-0.97$ \\
$70-74$ & 0.43 & $0.30-0.60$ \\
$75-79$ & 0.36 & $0.20-0.63$ \\
$80+$ & & \\
Sex & 1.00 & \\
Men & 1.96 & $1.53-2.52$ \\
Women & & \\
Place of Residence & 1.00 & $1.71-2.72$ \\
Rural & 2.16 & \\
Urban & & $0.47-0.97$ \\
Smoking & 1.00 & \\
Nonsmoker & 0.68 & $0.92-1.48$ \\
Smoker & & \\
Marrital Status & 1.00 & \\
No spouse & 1.17 & \\
Spouse & & \\
Education level & 1.00 & \\
Basic & 1.38 & \\
Moderate & 0.92 & \\
High & & \\
\hline
\end{tabular}

\footnotetext{
a Adjusted for all other variables in the table.

${ }^{b}$ Refers to participants with a body mass index $\geq 30 \mathrm{~kg} / \mathrm{m}^{2}$.

c Odds ratio.

${ }^{\mathrm{d}}$ Confidence interval.
} 
(95\% CI: $1.08-1.76)$ and 0.92 (95\% CI: 0.56- 1.52), respectively.

To investigate the weight gain across age groups among younger adults, another logistic model was applied, for which the data included 11206 women and 10479 men aged 20-59 years. Table 3 summarizes the adjusted odds ratios and their 95\% CI's. Using 20-29 years as the reference group, the obesity odds ratios were 2.29 (95\% CI: 2.06-2.56) for ages 30-39 years, 3.21 (95\% CI: $2.86-3.60)$ for ages $40-49$ years and 3.13 (95\% CI: 2.74-3.58) for ages 50-59 years.

\section{Discussion}

This cross-sectional study provided findings regarding the possible associations of some factors with obesity in older adults after the age of 60. Using 60-64 years as the reference group, the obesity odds ratios for age groups 65-69, 70-74, 75-79 and 80+ years were 0.86, 0.75, 0.43 and 0.36 , respectively. Obesity odds ratios were 1.96 for women, 2.16 for people living in urban areas, and 0.68 for smokers. Using basic education as the reference group, Obesity odds ratios for the moderate and high groups were 1.38 and 0.93 , respectively. Some of our results are consistent with other studies. Overall, 11.2\%

Table 3 Adjusted ${ }^{a}$ odds ratios for obesity ${ }^{b}$ among 24017 Iranian adults aged 20-59 years, National Health Survey in Iran, in the logistic analysis

\begin{tabular}{|c|c|c|}
\hline variable & $\mathrm{OR}^{\mathrm{c}}$ & $95 \% \mathrm{Cl}^{\mathrm{d}}$ \\
\hline \multicolumn{3}{|c|}{ Age group(years) } \\
\hline $20-29$ & 1.00 & \\
\hline $30-39$ & 2.29 & $2.06-2.56$ \\
\hline $40-49$ & 3.21 & $2.86-3.60$ \\
\hline $50-59$ & 3.13 & $2.74-3.58$ \\
\hline \multicolumn{3}{|l|}{ Sex } \\
\hline Men & 1.00 & \\
\hline Women & 2.76 & $2.49-3.05$ \\
\hline \multicolumn{3}{|c|}{ Place of Residence } \\
\hline Rural & 1.00 & \\
\hline Urban & 2.03 & $1.85-2.24$ \\
\hline \multicolumn{3}{|l|}{ Smoking } \\
\hline Nonsmoker & 1.00 & \\
\hline Smoker & 0.64 & $0.54-0.75$ \\
\hline \multicolumn{3}{|c|}{ Marrital Status } \\
\hline No spouse & 1.00 & \\
\hline Spouse & 1.16 & $1.05-1.29$ \\
\hline \multicolumn{3}{|c|}{ Education level } \\
\hline Basic & 1.00 & \\
\hline Moderate & 0.87 & $0.78-0.96$ \\
\hline High & 0.54 & $0.45-0.65$ \\
\hline
\end{tabular}

${ }^{a}$ Adjusted for all other variables in the table.

${ }^{\mathrm{b}}$ Refers to participants with a body mass index $\geq 30 \mathrm{~kg} / \mathrm{m}^{2}$.

c Odds ratio.

${ }^{\mathrm{d}}$ Confidence interval. of respondents were obese. The prevalence of obesity in older adult population varies enormously among countries. This prevalence in some Asian and African populations is $0 \%$ and in some industrial countries is more than $30 \%[3,4,33]$.

The findings show that in Iran people gain weight up to age of around 50-60 years old and after that BMI tends to decrease. Our results on the association between age and obesity are basically in line with some studies $[3,24,26,27]$. To gain a higher view of the relationship between obesity and age in older people, we have to understand the changes in food intake, energy expenditure, appetite and body composition (that occurs along with ageing) is inevitable. With aging, come bone and muscle losses that influence the body composition. After the age of 30, fat mass increases; whereas fat-free mass (FFM) progressively decreases. FFM (primarily skeletal muscle) decreases by up to $40 \%$ from age of 20 to 70 [25,34-36]. Maximal FFM is usually reached at age of 20-30 years, and maximal fat mass is usually reached at age of 60-70. After that, both fat measures subsequently decline $[25,34,35]$. Therefore, both decrease during old age.

In our present report, women were more likely by $96 \%$ to be obese. Elderly women tend to have higher prevalence of obesity than elderly men in most of the Latin American countries [37-39]. Regarding gender, our results are basically in line with these studies.

In our study, obesity was strongly associated with place of residence. Compared to rural elderly subjects, urban elderly subjects were twice as likely to be obese. The environment can influence access to healthy food, lifestyle behaviors such as the trend toward 'eating out', lack of sidewalks and accessible recreation areas. In a cohort study, Glass et al. found that neighborhood conditions can change the patterns of obesity [40]. The finding in the current research agrees with the observations by Gutierrez et al. [41] in some countries in Latin America and a population study conducted in Canada on the relationship between obesity and geographical region [24].

The results in our study suggested an inverse association between smoking and obesity. The inverse association seen between smoking and obesity should not be used to counteract the efforts undertaken against this habit, although smokers often report that they smoke to control their weight. Biological mechanisms as well as psychological factors may be involved. Smoking decreases appetite. Mineur et al. [42] showed that nicotine-induced, that reduces appetite, is due to hypothalamic melanocortin system. Gonseth et al. [43] found that some tobacco companies had added some substances into their cigarette in order to reduce smokers' appetite. An increase of energy expenditure while smoking, both 
in resting and in light physical activity conditions, may relate to lower prevalence of obesity in smokers. Our results are consistent with the findings of some studies $[24,28]$.

Although we did not find a significant association between marriage and obesity, Iranian elderly people who lived with their spouse were more likely to be obese than their unmarried counterparts. Kaplan et al. found that marriage was positively associated with obesity among older adult women but not men [24]. No evidence was found for an association between obesity and marital status in Taiwanese elderly people [44].

Using basic education as the reference group, our results showed that moderate educational level was associated with a higher likelihood for obesity. The inverse relationships between education status and obesity exist in some societies [3,24]. It is not a straightforward matter to compare those results with ours, due to the different study designs, time spans, regions, and methods of analysis. Our results are consistent with some studies in developing countries [44].

Our results are subjected to some limitations. This study is a cross-sectional study, which means that the direction of these associations cannot be conclusively determined and a causal relationship cannot be inferred but this should be confirmed by further longitudinal studies. We were not able to consider all of the risk factors that may be related to obesity. Income, eating behavior and physical activity were not used in our investigation. The consumption of alcohol is prohibited in Iran. Therefore we had no information on alcohol consumption. However, our study had several strengths. It was performed in a nationally representative sample of the Iranian older adults. To our knowledge, this is the first study that had a sample size sufficient to study factors related to obesity in older adults. This study included men and women aged 60 and over and our findings could be generalized to other people. Height and weight were actually measured rather than selfreported. It is well known that self-reports underestimate the prevalence of obesity $[45,46]$.

\section{Conclusions}

As the result of findings, we are optimistic that we would be able to contribute to the aged community of the society, which could be achieved by means of better treatments and reductions in the rate of obesity.

\section{Acknowledgements}

This work was supported by a grant from University of Social Welfare and Rehabilitation Sciences. We are also grateful to the National Health Survey for their data.

\section{Author details}

${ }^{1}$ Department of Statistics and Computer, University of Social Welfare and Rehabilitation Sciences, Tehran, Iran. ${ }^{2}$ Department of Physiology, Medicine School, Tehran University of Medical Sciences, Iran. ${ }^{3}$ Department of Biostatistics, School of Public Health and Institute of Public Health Research, Tehran University of Medical Sciences, Iran.

\section{Authors' contributions}

EB and KM originated the idea for this study, did the research proposal, data analysis and prepared the manuscript. AB co-ordinated the research project, while BS helped and edited the final as the physiology consultant. All authors read and approved the final manuscript.

\section{Competing interests}

The author declares that they have no competing interests.

Received: 5 July 2011 Accepted: 14 December 2011

Published: 14 December 2011

\section{References}

1. [http://www.who.int/mediacentre/factsheets/fs311/en/index.html].

2. Kopelman PG: Obesity as a medical problem. Nature 2000, 404(6778):635-643.

3. Gutierrez-Fisac JL, Lopez E, Banegas JR, Graciani A, Rodriguez-Artalejo F: Prevalence of overweight and obesity in elderly people in Spain. Obes Res 2004, 12(4):710-715.

4. Ogden CL, Carroll MD, Curtin LR, McDowell MA, Tabak CJ, Flegal KM: Prevalence of overweight and obesity in the United States, 1999-2004. JAMA 2006, 295(13):1549-1555.

5. Brown JS, Seeley DG, Fong J, Black DM, Ensrud KE, Grady D: Urinary incontinence in older women: who is at risk? Study of Osteoporotic Fractures Research Group. Obstet Gynecol 1996, 87(5 Pt 1):715-721.

6. Dwyer PL, Lee ET, Hay DM: Obesity and urinary incontinence in women. Br J Obstet Gynaecol 1988, 95(1):91-96.

7. Ford ES: Body mass index and colon cancer in a national sample of adult US men and women. Am J Epidemiol 1999, 150(4):390-398.

8. Glynn RJ, Christen WG, Manson JE, Bernheimer J, Hennekens CH: Body mass index. An independent predictor of cataract. Arch Ophthalmol 1995, 113(9):1131-1137.

9. Hiller R, Podgor MJ, Sperduto RD, Nowroozi L, Wilson PW, D'Agostino RB, Colton T: A longitudinal study of body mass index and lens opacities. The Framingham Studies. Ophthalmology 1998, 105(7):1244-1250.

10. Huang Z, Willett WC, Manson JE, Rosner B, Stampfer MJ, Speizer FE, Colditz GA: Body weight, weight change, and risk for hypertension in women. Ann Intern Med 1998, 128(2):81-88.

11. Kannel WB, D'Agostino RB, Cobb JL: Effect of weight on cardiovascular disease. Am J Clin Nutr 1996, 63(3 Suppl):419S-422S.

12. McCarthy LH, Bigal ME, Katz M, Derby C, Lipton RB: Chronic pain and obesity in elderly people: results from the Einstein aging study. $J \mathrm{Am}$ Geriatr Soc 2009, 57(1):115-119.

13. Milionis HJ, Florentin M, Giannopoulos S: Metabolic syndrome and Alzheimer's disease: a link to a vascular hypothesis? CNS Spectr 2008, 13(7):606-613

14. Mommsen S, Foldspang A: Body mass index and adult female urinary incontinence. World J Urol 1994, 12(6):319-322.

15. Olesen M, Gudmand-Hoyer E: Efficacy, safety, and tolerability of fructooligosaccharides in the treatment of irritable bowel syndrome. Am J Clin Nutr 2000, 72(6):1570-1575.

16. Resnick HE, Valsania P, Halter JB, Lin X: Relation of weight gain and weight loss on subsequent diabetes risk in overweight adults. J Epidemiol Community Health 2000, 54(8):596-602.

17. Roberts RE, Kaplan GA, Shema SJ, Strawbridge WJ: Are the obese at greater risk for depression? Am J Epidemiol 2000, 152(2):163-170

18. Tikkinen KA, Auvinen A, Huhtala H, Tammela TL: Nocturia and obesity: a population-based study in Finland. Am J Epidemiol 2006, 163(11):1003-1011

19. van den Brandt PA, Spiegelman D, Yaun SS, Adami HO, Beeson L, Folsom AR, Fraser G, Goldbohm RA, Graham S, Kushi L, et al: Pooled analysis of prospective cohort studies on height, weight, and breast cancer risk. Am J Epidemiol 2000, 152(6):514-527. 
20. McGinnis JM, Foege WH: Actual causes of death in the United States. JAMA 1993, 270(18):2207-2212.

21. Flegal KM, Graubard BI, Williamson DF, Gail MH: Excess deaths associated with underweight, overweight, and obesity. JAMA 2005, 293(15):1861-1867.

22. Reynolds SL, Saito Y, Crimmins EM: The impact of obesity on active life expectancy in older American men and women. Gerontologist 2005, 45(4):438-444.

23. Himes $C L$ : Obesity, disease, and functional limitation in later life. Demography 2000, 37(1):73-82.

24. Kaplan MS, Huguet N, Newsom JT, McFarland BH, Lindsay J: Prevalence and correlates of overweight and obesity among older adults: findings from the Canadian National Population Health Survey. J Gerontol A Biol Sci Med Sci 2003, 58(11):1018-1030.

25. Villareal DT, Apovian CM, Kushner RF, Klein S: Obesity in older adults: technical review and position statement of the American Society for Nutrition and NAASO, The Obesity Society. Am J Clin Nutr 2005, 82(5):923-934.

26. Chapman IM: Obesity in old age. Front Horm Res 2008, 36:97-106.

27. Flegal KM, Carroll MD, Kuczmarski RJ, Johnson CL: Overweight and obesity in the United States: prevalence and trends, 1960-1994. Int J Obes Relat Metab Disord 1998, 22(1):39-47.

28. Kruger J, Ham SA, Prohaska TR: Behavioral risk factors associated with overweight and obesity among older adults: the 2005 National Health Interview Survey. Prev Chronic Dis 2009, 6(1):A14..

29. Bakhshi E, Mohammad K, Eshraghian MR, Seifi B: Factors related to obesity among Iranian men: results from the National Health Survey. Public Health Nutr 13(9):1389-1394.

30. Bakhshi E, Eshraghian MR, Mohammad K, Seifi B: A comparison of two methods for estimating odds ratios: results from the National Health Survey. BMC Med Res Methodol 2008, 8:78.

31. Bakhshi E, Eshraghian MR, Mohammad K, Foroushani AR, Zeraati $H$, Fotouhi A, Siassi F, Seifi B: The positive association between number of children and obesity in Iranian women and men: results from the National Health Survey. BMC Public Health 2008, 8:213.

32. Bakhshi E, Eshraghian MR, Mohammad K, Foroushani AR, Zeraati $H$, Fotouhi A, Siassi F, Seifi B: Sociodemographic and smoking associated with obesity in adult women in Iran: results from the National Health Survey. J Public Health (Oxf) 2008, 30(4):429-435.

33. Launer $\sqcup$, Harris T: Weight, height and body mass index distributions in geographically and ethnically diverse samples of older persons. Ad Hoc Committee on the Statistics of Anthropometry and Aging. Age Ageing 1996, 25(4):300-306.

34. Baumgartner RN, Stauber PM, McHugh D, Koehler KM, Garry PJ: Crosssectional age differences in body composition in persons $60+$ years of age. J Gerontol A Biol Sci Med Sci 1995, 50(6):M307-316.

35. Gallagher D, Visser M, De Meersman RE, Sepulveda D, Baumgartner RN, Pierson RN, Harris T, Heymsfield SB: Appendicular skeletal muscle mass: effects of age, gender, and ethnicity. J Appl Physiol 1997, 83(1):229-239.

36. Flynn MA, Nolph GB, Baker AS, Martin WM, Krause G: Total body potassium in aging humans: a longitudinal study. Am J Clin Nutr 1989, 50(4):713-717.

37. Abrantes MM, Lamounier JA, Colosimo EA: [Overweight and obesity prevalence in Northeast and Southeast Regions of Brazil]. Rev Assoc Med Bras 2003, 49(2):162-166.

38. Barbosa AR, Santarem JM, Jacob Filho W, Meirelles ES, Marucci JM: [Comparison of body fat using anthropometry bioelectrical impedance and DEXA in elderly women]. Arch Latinoam Nutr 2001, 51(1):49-56.

39. Barreto SM, Passos VM, Lima-Costa MF: Obesity and underweight among Brazilian elderly: the Bambui Health and Aging Study. Cad Saude Publica 2003, 19(2):605-612.

40. Glass TA, Rasmussen MD, Schwartz BS: Neighborhoods and obesity in older adults: the Baltimore Memory Study. Am J Prev Med 2006, 31(6):455-463.

41. Gutierrez LM, Llaca MC, Cervantes L, Velasquez Alva MC, Irigoyen ME, Zepeda M: Overweight in elderly Mexican women of a marginal community. J Nutr Health Aging 2001, 5(4):256-258.

42. Mineur YS, Abizaid A, Rao Y, Salas R, DiLeone RJ, Gundisch D, Diano S, De Biasi M, Horvath TL, Gao XB, et al: Nicotine decreases food intake through activation of POMC neurons. Science 332(6035):1330-1332.
43. Gonseth S, Jacot-Sadowski I, Diethelm PA, Barras V, Cornuz J: The tobacco industry's past role in weight control related to smoking. Eur J Public Health 2011

44. Lin CC, Li TC, Lai SW, Li Cl, Wanga KC, Tan CK, Ng KC, Liu CS: Epidemiology of obesity in elderly people. Yale J Biol Med 1999, 72(6):385-391.

45. Bostrom G, Diderichsen F: Socioeconomic differentials in misclassification of height, weight and body mass index based on questionnaire data. Int J Epidemiol 1997, 26(4):860-866.

46. Kuskowska-Wolk A, Bergstrom R, Bostrom G: Relationship between questionnaire data and medical records of height, weight and body mass index. Int J Obes Relat Metab Disord 1992, 16(1):1-9.

doi:10.1186/1756-0500-4-538

Cite this article as: Bakhshi et al:: Factors associated with obesity in Iranian elderly people: Results from the National Health Survey. BMC Research Notes 2011 4:538.

\section{Submit your next manuscript to BioMed Central and take full advantage of:}

- Convenient online submission

- Thorough peer review

- No space constraints or color figure charges

- Immediate publication on acceptance

- Inclusion in PubMed, CAS, Scopus and Google Scholar

- Research which is freely available for redistribution

Submit your manuscript at www.biomedcentral.com/submit
Ciomed Central 